\title{
Dossiê
}

\section{Regionalismo partidário e populismo no Brasil: análise da nacionalização dos partidos da democracia de 1945-1964}

\author{
Party regionalism and populism in Brazil: analysis \\ of nationalization of parties of the democracy \\ 1945-1964
}

\author{
Bruno da Silva Conceição \\ Doutorando, Universidade Federal do Rio Grande do Sul (UFRGS), \\ Programa de Pós-graduação em Ciência Política (PPGCPOL), \\ Porto Alegre, RS, Brasil \\ brunopolitica@gmail.com
}

\begin{abstract}
Resumo: $\bigcirc$ artigo discute os efeitos do populismo na vida partidária da democracia de 1945-1964 no Brasil. A possível regionalização dos partidos da democracia de 1945-1964 teria sido um dos fatores a contribuir para o fim deste sistema partidário? O argumento dessa pesquisa é de que a nacionalização dos partidos, a capacidade de os partidos possuírem uma homogeneização de votos pelos estados, teria sido reduzida quando estivesse presente, dentro das legendas, a figura de políticos com perfil populista. A metodologia aqui utilizada para mensurar a nacionalização partidária é o Party Nationalization Score (PNS) que adapta o coeficiente de Gini para mensurar a dispersão/concentração de votos, de cada partido, em cada estado. Este índice promove uma escala de valores, entre 0 e 1, onde os partidos que atinjam valores próximos de 1 correspondem a nacionalização partidária, enquanto valores que se aproximem de 0 indicam regionalização partidária. Os dados aqui utilizados são provenientes do repositório de dados do Tribunal Superior Eleitoral (TSE). Os resultados desta pesquisa indicam que a presença de políticos com perfil populista no sistema partidário não afetou negativamente a nacionalização dos partidos da época (PSD, UDN, PTB, PSP, PST, PDC e PTN).
\end{abstract}

Palavras-chave: Populismo; Nacionalização partidária; Regionalismo partidário; Democracia 1945-1964. 
T\&P Regionalismo partidário e populismo no Brasil: análise da nacionalização dos partidos da democracia de 1945-1964

\begin{abstract}
The article discusses the effects of populism on the party life of the democracy 1945-1964 in Brazil. Could the possible regionalization of the democracy 1945-1964 parties have been one of the factors contributing to the end of this party system? The argument of this research is that the nationalization of the parties, the ability of the parties to have a homogenization of votes by the states, would have been reduced when the figure of politicians with a populist profile was present within the legends. The methodology used to measure party nationalization is the Party Nationalization Score (PNS), which adapts the Gini coefficient to measure the dispersion / concentration of votes of each party in each state. This index promotes a scale of values between 0 and 1 , where the parties that reach values close to 1 correspond to party nationalization, while values that approach 0 indicate party regionalization. The data used here come from the data repository of the Superior Electoral Court (TSE). The results of this research indicate that the presence of politicians with a populist profile in the party system did not negatively affect the nationalization of the parties of the time (PSD, UDN, PTB, PSP, PST, PDC and PTN).
\end{abstract}

Keywords: Populism; Party nationalization; Party regionalism; Democracy 1945-1964.

\title{
Introdução
}

Os principais partidos da democracia de 1945-1964 eram aqueles com clara inspiração getulista, favorável ou contrária ao famoso líder político, e que constantemente entravam em conflito nas eleições pelo cargo de Presidente da República, quais sejam: o Partido Social Democrático (PSD), o Partido Trabalhista Brasileiro (PTB) e a União Democrática Nacional (UDN). Uma tese bastante defendida pelos pesquisadores desse período era de que se o sistema partidário tivesse sobrevivido a sua abrupta interrupção, ocasionada pelo golpe civil-militar de 1964, haveria uma provável alteração na dinâmica de forças entre os partidos. Sob a liderança do PTB, houve o crescimento eleitoral dos partidos progressistas, em razão da expansão do sufrágio universal para a classe operária emergente no Brasil, que somado ao discurso populista, em alta no cenário sul-americano, estaria prestes a ocasionar uma derrocada dos partidos conservadores e dos políticos tradicionais brasileiros na década de 1960 (BENEVIDES, 1981; HIPPOLITO, 1985; CAMPELO DE SOUZA, 1985, D'ARAÚJO, 1996; LAVAREDA, 1999; SOARES, 2001).

Dessa forma, o golpe civil-militar de 1964 teria sido um modo de conter a perda de espaço das elites tradicionais na política nacional e, ainda mais importante, barrar a ascensão de líderes populistas, posicionados à esquerda ou à direita, que poderiam maximizar suas chances de ascender à chefia do Executivo nacional nas eleições presidenciais marcadas para 1965. Quanto desse diagnóstico sobre a crise institucional deste sistema partidário ainda perdura? O populismo seria um fenômeno conectado a regionalização do conflito político? O populismo seria um fenômeno que sobrevaloriza a 
força do partido no qual há um político carismático? A fraca nacionalização dos partidos da democracia de 1945-1964 teria sido um dos fatores a contribuir para o fim deste sistema partidário?

O argumento aqui posto é de que a nacionalização dos partidos, ou seja, a capacidade de os partidos possuírem uma homogeneização de votos pelos estados foi reduzida quando esteve presente, dentro das legendas, a figura de políticos com perfil populista. Quanto mais o partido consegue se afastar de membros partidários com este perfil no comando das legendas, mais tenderia a ter uma penetração de votos por todo o território, ao invés de uma força eleitoral concentrada em poucas regiões.

Descrito apenas como uma prática política para manipular os eleitores em prol dos interesses individuais dos políticos, busco testar se os efeitos do estilo populista de ação são notados no enfraquecimento da organização partidária, não somente nos eleitores, já que a imagem do líder carismático poderia enfraquecer o surgimento de novas lideranças e, consequentemente, a competitividade partidária por novos sufrágios. Partidos com lideranças populistas seriam suscetíveis de relações mais clientelistas com eleitores, estas relações pautadas pelas promessas feitas pelos representantes. Assim, as eleições parlamentares estariam em segundo plano frente a conquista pessoal, dos líderes carismáticos da sigla, por alguns estados ou, no caminho mais difícil, pela Presidência da República. A capacidade de nacionalização partidária seria um antídoto aos oligopólios de elites locais e do clientelismo político (SCHATTSCHNEIDER, 1960).

O objetivo dessa pesquisa é mensurar em quais polos (nacionalização ou regionalismo) os partidos desse período estavam mais próximos e ver se a presença de políticos populistas impediu, ou não, a nacionalização destes partidos. Para tal análise, observo a força eleitoral pelo território dos partidos que tiveram expoentes políticos designados como populistas: Getúlio Vargas no Partido Trabalhista Brasileiro (PTB); Jânio Quadros no Partido Democrata Cristão e no Partido Trabalhista Nacional (PDC/PTN); Adhemar de Barros no Partido Social Progressista (PSP), Carlos Lacerda na União Democrática Nacional (UDN), Miguel Arraes no Partido Social Trabalhista (PST) e Leonel Brizola no Partido Trabalhista Brasileiro (PTB). Estes políticos selecionados são considerados como modelos exemplares do conceito de populismo: relação direta com um conjunto de eleitores propensos a creditar seu sufrágio em razão do carisma pessoal do que pela afinidade 
T\&P Regionalismo partidário e populismo no Brasil: análise da nacionalização dos partidos da democracia de 1945-1964

partidária, além de uma idealização dos adversários políticos, reais ou inventados, como inimigos dos interesses do povo (WEFFORT, 1978; PANIZZA, 2005; DEBERT, 2008).

O texto está dividido em quatro seções. Na primeira seção, faço uma recapitulação das origens do regionalismo partidário e do populismo no Brasil. Depois, traço uma breve biografia política dos líderes populistas daquela época. Na terceira seção, apresento os aportes teóricos-metodológicos para mensurar a nacionalização ou regionalização dos partidos da democracia de 1945-1964. Na seção seguinte, faço uma análise geral dos resultados eleitorais dos principais partidos com base nos dados empíricos das disputas para a Câmara dos Deputados, utilizando a correção dos dados feitas por Jairo Nicolau (2004), e das disputas para as Assembleias Estaduais disponibilizados pelo Tribunal Superior Eleitoral (TSE).

\section{Origens do regionalismo partidário e do populismo na política brasileira}

Desde o término do Império (1822-1889), os regionalismos políticos tiveram alta influência na vida política nacional. Na Primeira República (1889-1930), designada por vezes como República Velha, houve a efetivação de uma organização política descentralizada nos estados ocasionada a partir da promulgação da Constituição de 1891. Conforme Gláucio Soares (2001), na Constituição de 1891 foram estabelecidas prerrogativas legais para que os estados tivessem plena autonomia administrativa. A Constituição de 1891 favoreceu que as agendas dos Executivos estaduais fossem postas em prática em cada estado, fortalecendo, em grande medida, os governos mais desenvolvidos na esfera econômica, casos de São Paulo e Minas Gerais, ao propiciar maior arrecadação de impostos e, em conjunto, a liberdade de formação de efetivos militares autônomos da dependência central, sendo notório, por exemplo, o poderio militar do Rio Grande do Sul, devido a este ser um estado fronteiriço com outros países. As oligarquias estaduais, outrora subservientes ao Imperador Dom Pedro II, agora negociavam de igual para igual com o governo central já que, em alguns casos, o potencial econômico ou os efetivos militares estaduais superavam ou rivalizavam com a capacidade do governo federal (SOARES, 2001). 
A vida política era calcada na "política dos Governadores", ou "política dos estados", como preferia chamar o Presidente Campos Sales. As oligarquias estaduais estavam interessadas tão somente na política local do que em alavancar carreiras pessoais em nível nacional. O cabedal de sufrágios que sancionava a votação dos governantes estaduais era adquirido pela dominação e usurpação das máquinas públicas, onde os governadores colocavam seus subalternos e aliados através de práticas patrimonialistas. Um retrato do regionalismo político podia ser visto nos partidos com atuação restrita a seus respectivos estados, sem se importar em criar uma organização partidária de âmbito nacional. Os parlamentares de cada estado, na Câmara dos Deputados, comportavam-se direcionados para suas clientelas locais sem qualquer intervenção federal. No entanto, a contrapartida requerida pelo Presidente da República era o apoio dos parlamentares estaduais, sem hesitações, aos projetos do Executivo no Congresso (CAMPELO DE SOUZA, 1969; NICOLAU, 2012; RICCl; ZULINI, 2014).

Uma ressalva quanto ao viés "democrático" da Primeira República deve ser feita, pois é difícil enquadrar esta fase política como um período democrático no sentido mínimo de democracia procedimental. Havia a existência generalizada de visíveis fraudes eleitorais, intimidação de eleitores, voto coercitivo, corrupção, etc. Dentro da lógica do clientelismo, os políticos que queriam uma projeção na carreira precisavam da votação controlada pelos "coronéis", que possuíam vários votos dos moradores no entorno dos seus domínios. Em troca dos votos e do apoio ao Presidente da República, aos Presidentes de Províncias e aos deputados federais, a classe política concedia total liberdade de ação aos "coronéis" dentro dos seus respectivos territórios. Assim desenrolava as eleições nos municípios, ou seja, extremamente manipuladas (LEAL, 1975).

As características prevalecentes na República Velha foram de dominação política oligárquica, na maior parte dos estados, e de realização periódica de eleições quase sempre fraudulentas. Este cenário oligárquico só foi alterado com a crise que afetou a relação dos estados-chave que mantinham a política econômica nacional do "café com leite", respectivamente, São Paulo e Minas Gerais. O descontentamento dos estados mais pobres com a assimetria de poder de paulistas e mineiros, além da própria crise entre os parceiros com relação a alternância presidencial, possibilitou a articulação de uma "Revolução" em 1930. Liderada pelo Rio Grande do Sul, com o suporte de Minas 
T\&P Regionalismo partidário e populismo no Brasil: análise da nacionalização dos partidos da democracia de 1945-1964

Gerais e outros estados menores, esta revolução terminou por desfazer a República Oligárquica (SOARES, 2001).

A Era Vargas (1930-1945) simbolizou a contenção dos regionalismos políticos para o controle político vertical representado na imagem do Presidente da República. Após a deposição das antigas elites estaduais seguiu um período de governo provisório (1930-1937) até se chegar a um sistema político autoritário visto no Estado Novo Varguista (1937-1945). A Constituição de 1937 determinou a suspensão dos partidos políticos interrompendo qualquer perspectiva de um novo realinhamento político que priorizasse a esfera estadual frente à esfera nacional. A clandestinidade tornou-se uma opção para grupos políticos manterem-se coesos em razão das perseguições ideológicas do regime ditatorial. Esse foi o caso do Partido Comunista Brasileiro. Somente com a intervenção militar que depôs Getúlio Vargas, motivada pelas repercussões do fim da Segunda Guerra Mundial, houve a possibilidade de abertura política e do reaparecimento da dimensão competitiva de partidos políticos no Brasil.

O começo de uma estruturação do sistema partidário brasileiro acontece no período de 1945-1964. Durante essa curta experiência democrática houve uma configuração partidária, em vias de consolidação. Este ciclo democrático trouxe uma nova configuração dos partidos políticos passando de seções estaduais, outrora sem conexão regional, para seções nacionais interligadas pela busca de sucesso eleitoral. Ainda que alguns partidos fossem regionalizados na seleção de seus candidatos, fornecendo ao Congresso somente representantes eleitos de apenas um ou dois estados, os partidos desse período eram obrigados a ter uma estrutura organizativa nacional, mesmo que precária.

A competitividade sem manipulações eleitorais é importante para compreender a direção populista da época. A criação dos partidos esteve conectada com o retorno de oligarquias estaduais para a competição versus os interesses de manutenção no poder dos interventores estaduais nomeados por Vargas. A imprevisibilidade do resultado dependia de quanto o alistamento eleitoral conseguiria ser feito de maneira rápida e eficaz, para que políticos locais não criassem clientelas, somado com uma legislação eleitoral rígida que não fosse elaborada, de forma exclusiva, pela classe política dominante durante o Estado Novo (LIMONGI, 2015).

1 Artigo 178 - São dissolvidos nesta data a Câmara dos Deputados, o Senado Federal, as Assembleias Legislativas dos Estados e as Câmaras Municipais. As eleições ao Parlamento nacional serão marcadas pelo Presidente da República, depois de realizado o plebiscito a que se refere o art. 187. Texto Constitucional de 1937. 
A Constituição de 1946 concedia certa autonomia administrativa aos entes federativos, estaduais e municipais, mas intervia na competição política ao proibir a reeleição² para os cargos majoritários. Em parte, a proibição da reeleição incentivou os políticos mais ambiciosos a subirem cada vez mais de posto já que a manutenção do poder, em cada estado, era dificultada pela necessidade de criar um sucessor que não competisse, em popularidade, com o atual mandatário do Executivo estadual. Tal conjuntura propiciou a ascensão de um novo jeito de fazer política, desvinculado da intermediação partidária para comunicação com o povo, no sentido de que os políticos não precisavam mais da autorização dos caciques partidários para interagir com a população. Agora o contato do político era feito diretamente com o povo, via comícios ou através dos meios de comunicação (rádio e jornais). A capacidade de interlocução do político carismático com o povo, desvinculada das bênçãos dos caciques estaduais, trazia dividendos para os políticos mais habilidosos.

Contudo, isso poderia diminuir a articulação partidária, pois na democracia de 1945-1964 os partidos saíam do status individual e local, característico da Primeira República, para serem organizações que deveriam ter representação por todo o território. Fernando Limongi (2015) aponta, por exemplo, que grande parte dos sufrágios do PTB, em 1945, para a Câmara dos Deputados dependeu da presença impactante de Getúlio Vargas, saindo candidato pela sigla em poucos estados, se comparado com outros partidos que tinham uma coordenação eleitoral para lançar candidatos por todos os entes federativos. Se em um primeiro momento a interferência de Vargas afetou positivamente os resultados eleitorais do PTB, a longo prazo, no entanto, a permanência desse político talvez atrapalhasse os planos de nacionalização em razão de uma falta de preocupação por recrutar novas lideranças.

O sucesso de alguns políticos populistas possibilitava que sonhassem com a Presidência da República, já que era vedado permanecerem nos governos estaduais em mandatos consecutivos, ou seja, o poder estadual só voltaria depois de um intervalo no cargo. Dos políticos designados como populistas, três deles concorreram em pleitos presidenciais (Vargas, Quadros e Barros), dois deles tornaram-se Presidentes da

2 Art. $7^{\circ}$ - O Governo Federal não intervirá nos Estados salvo para: VII - assegurar a observância dos seguintes princípios: a) forma republicana representativa; b) independência e harmonia dos Poderes; c) temporariedade das funções eletivas, limitada a duração destas à das funções federais correspondentes; d) proibição da reeleição de Governadores e Prefeitos para o período imediato; e) autonomia municipal; f) prestação de contas da administração; g) garantias do Poder Judiciário. Texto Constitucional de 1946. 
T\&P Regionalismo partidário e populismo no Brasil: análise da nacionalização dos partidos da democracia de 1945-1964

República (Vargas e Quadros) e três deles almejavam o posto antes do golpe de 1964 (Arraes, Lacerda e Brizola). Esse estilo de fazer política ganhou contemporaneamente um aspecto negativo na sociedade, mesmo que nas décadas de 1950 e 1960 não tivessem uma conotação pejorativa nos órgãos de imprensa (FERREIRA, 2001; CERVI, 2001).

Mas, afinal, qual seria a definição de populismo? Uma definição consagrada é aquela posta por Francisco Weffort que concebe o fenômeno do populismo como: "[...] é, no essencial, a exaltação do poder público; é o próprio Estado colocando-se através do líder, em contato direto com os indivíduos reunidos na massa" (WEFFORT, 1978, p. 28). Para Weffort, o líder populista usa do seu prestígio com a população para alcançar o controle da máquina estatal. O usufruto das benesses estatais só pode ser adquirido, pelo povo, por meio da mediação do líder carismático. É uma relação passiva das massas que não conquista nada, e sim, depende de uma capacidade do político populista efetivar promessas feitas ou durante as campanhas eleitorais, ou durante seu mandato.

O conceito de populismo foi bastante usado na literatura acadêmica brasileira do século XX para definir o período democrático de 1945-1964. Segundo Ângela Gomes (2001), este conceito teve bastante aceitação entre os intelectuais das décadas de 1950, 1960 e 1970, pois descreve em detalhes a relação assimétrica entre o Estado e o povo. A autora destaca que os autores pioneiros nos estudos sobre o populismo, - entre eles estão Alberto Guerreiro Ramos, Hélio Jaguaribe e, o mais destacado deles, Francisco Weffort -, tinham várias concepções negativas sobre o conceito. Entre os fatores que propiciavam o estilo populista de fazer política no cenário brasileiro estavam: a) uma perspectiva sócio histórica de configuração das "massas", - sem uma definição adequada do que significa "massas"-, que seriam incorporadas no setor industrial, mas que nesse contato entre operários e trabalhadores rurais, estes últimos contaminariam os primeiros com um comportamento passivo ao Estado; b) a influência da teoria da modernização cujo o argumento central afirma que os países em desenvolvimento só iriam passar para um modelo de sociedade urbana, de economia próspera e de participação social, se tivessem deixado para trás o seu legado tradicional e agrário, dessa forma o populismo seria a manifestação dessa mudança de uma sociedade simples para uma sociedade mais complexa; c) a manipulação política dos líderes políticos carismáticos sobre as "massas" que não teriam consciência de classe e aceitariam discursos vazios de conteúdo; e d) o descrédito dos partidos políticos e do Congresso nos primeiros anos democráticos, em razão do fraco crescimento econômico durante os anos 
Dutra (1945-1950), possibilitaram que políticos carismáticos tivessem mais prestígio e legitimidade que os políticos tradicionais.

Houve contestações em relação a algumas dessas premissas, pois era preciso acrescentar outros fatores para o aparecimento do populismo na política brasileira, quais sejam: a) a repressão estatal sobre os sindicatos na Era Vargas que desestimulou a organização dos trabalhadores por muito tempo, favorecendo a manipulação política dos trabalhadores associada com a satisfação de algumas demandas sociais; b) o populismo é um fenômeno que só ocorreria dentro do sistema capitalista aonde a autoridade tradicional é substituída pela confiança do voto; c) a progressiva expansão do sufrágio eleitoral que colocou um novo contingente de eleitores na política sem uma experiência anterior de escolha de governantes propensos a aceitar as promessas desses líderes populistas; e d) a assimetria entre Estado e povo permitiu a confluência de um líder carismático capaz de mobilizar a classe trabalhadora, desorganizada e insatisfeita socialmente, em um pacto de apoio ao político populista em troca de favores estatais. Todo esse contato entre líder e massas sobrepuja a mediação dos partidos que estariam desacreditados, ou marcados como corruptos ou ineficazes, facilitando a dependência da população às promessas dos líderes populistas.

O sucesso dos políticos populistas decorre do cumprimento mínimo de promessas, econômicas ou de direitos sociais, e de políticas públicas para o povo. Uma relação claramente assimétrica de poder, mas que requer um controle popular de pressão para que o discurso dos líderes populistas não seja vazio de conteúdo. Por de trás da aparente demagogia dos líderes populistas daquela época existia uma contrapartida mínima que beneficiava a população (GOMES, 2001; CERVI, 2001).

Francisco Weffort (1978), principal ideólogo brasileiro do conceito de populismo, aponta que as características industriais e de urbanização nas grandes metrópoles favoreceram o aparecimento desse tipo de político. Essa relação difere bastante do que acontecia na República Velha, onde os coronéis controlavam os habitantes da região pela coerção social, psicológica e econômica. Isto fica nítido no trecho, a seguir, sobre as diferenças entre coronelismo e populismo:

Populismo e'coronelismo'assemelham-se num ponto: ambos incluem alguma forma de identificação pessoal na relação entre o chefe e a base. Trata-se, porém, no fundamental, de realidades sociais diferentes. $O$ populismo é fenômeno das regiões atingidas pela intensificação do processo de urbanização. Estabelece suas raízes mais fortes em São Paulo, 
T\&P Regionalismo partidário e populismo no Brasil: análise da nacionalização dos partidos da democracia de 1945-1964

região de mais intenso desenvolvimento industrial no país. Deste modo, a relação lídermassa típica do populismo apenas formalmente se assemelha aos padrões tradicionais vigentes na velha sociedade agrária brasileira. (WEFFORT, 1978, p. 28).

Para Weffort (1978), o discurso populista não apresentaria conteúdo ideológico já que vários autores"definem, em geral, o populismo pelos seus aspectos exteriores - a demagogia, a emocionalidade, a verbiagem social - etc. e especialmente pela 'ausência de ideologia'. O populismo seria, então, mera exterioridade, fato político sem conteúdo" (WEFFORT, 1978, p. 25). Segundo Weffort (1978), quando os partidos são fracos, frágeis e ineficientes, o voto tende a transformar a relação política numa relação entre indivíduos. Em suma, uma relação clientelista do líder carismático com a população. A massa seria influenciada para a ação política, apenas, pelo sufrágio.

No entanto, é pertinente a crítica de que a massa trabalhadora não seria tão ingênua para ser manipulada como conviesse. Conforme Gomes (2001), uma das principais explicações para o golpe civil-militar de 1964 reside também no esgotamento do pacto entre líderes populistas e suas promessas às classes trabalhadoras. A hesitação do Presidente João Goulart em tomar medidas radicais para a classe trabalhadora favoreceu uma tomada de poder dos militares já que o apoio da população desapareceu. Ou seja, quando a massa percebe que suas demandas não são atendidas pelo político este vínculo entre Estado e povo desaparece.

Por fim, uma menção crítica ao conceito de populismo já que este termo é cercado de controvérsias de definição entre os pesquisadores de Ciência Política (PANIZZA, 2005; LACLAU, 2005). Francisco Panizza (2005) salienta que este conceito sofre de contestações conceituais iguais ao que ocorre com o conceito de democracia sendo, portanto, de difícil mensuração. Nos termos de Ernesto Laclau (2005), a característica principal do populismo é ser uma articulação política, um modo de fazer política sem estar relacionado, a priori, com questões ideológicas. O conceito de populismo seria um recurso analítico para a Ciência Política, em qualquer tempo, quando um discurso político separa a população entre, de um lado, o povo, e, de outro lado, seus antagonistas. O político populista seria aquele que maneja essa dicotomia de forma a sustentar uma defesa do povo contra esse inimigo dos anseios populares. 
O populismo é, portanto, um modo de identificação disponível para qualquer ator político operando em um campo discursivo em que a noção de soberania do povo e seu corolário inevitável, o conflito entre os poderosos e os fracos, são elementos centrais do seu imaginário político. (PANIZZA, 2005, p. 4) $)^{3}$.

Panizza (2005) aborda que políticos definidos como populistas de "direita" poderiam identificar o povo, na sua interlocução com o público, como aqueles preocupados com os valores tradicionais e nacionalistas, enquanto "os outros" seriam aqueles dispostos a entregar o país ou sacrificar os valores tradicionais da família. De outro lado, os populistas de "esquerda" seriam aqueles que almejam ascender o povo ao poder real que lhe é negado pela aristocracia gananciosa representada, ora pelo organismo financeiro, ora pela iniciativa privada ou pelos políticos tradicionais que permanecem ocupando os principais cargos públicos, de maneira sucessiva, sem modificar a realidade da população pobre. Em comum nos dois modelos de populismo, está a articulação política do líder carismático separando o povo, uma fatia da população plenamente identificada com o líder populista, daqueles "inimigos" do povo, ou seja, a outra fatia do eleitorado que discorda das intenções do líder carismático.

Entre outras críticas aos políticos populistas, é de que tratariam a classe trabalhadora como ingênua e manipulável, gerando a culpabilidade que, hoje em dia, os políticos alinhados ao estilo populista sofrem, de parte da opinião pública, de falta de cumprimento de promessas de campanha e de denúncias de má administração pública. É um ponto de vista problemático para encarar a forma de governo destes líderes carismáticos. Por que um político não privilegiaria aquela fatia do eleitorado que asseguraria sua continuidade no poder? Adotar um caminho diferente, no passado, seria equivocado em uma época de tensão entre a classe política e os setores militares. A sustentação dos Presidentes da República residiu, basicamente, na comunicação com o eleitorado já que vários deles sofreram tentativas de golpe de estado.

Esse retorno do contato com benesses estatais ou serviços públicos mediados pelo político para a população, característica presente desde os tempos da Primeira República, possibilita relacionar o regionalismo e o populismo como fenômenos complementares sobre o aspecto clientelista. Isto pode ser um dos principais impeditivos para que os

3 No original:"Populism is thus a mode of identification available to any political actor operating in a discursive field in which the notion of the sovereignty of the people and its inevitable corollary, the conflict between the powerful and the powerless, are core elements of its political imaginary". 
T\&P Regionalismo partidário e populismo no Brasil: análise da nacionalização dos partidos da democracia de 1945-1964

partidos alcancem maiores fatias do eleitorado e acirre os ânimos das elites estaduais que assistem uma massa de eleitores recebendo direitos sociais que antes eram exclusivos de um grupo social. Tal fato faz com que estes políticos populistas, descritos a seguir, sejam vistos com muita desconfiança pela classe média, por setores religiosos e pelas Forças Armadas como ameaças ao status quo.

\section{Os líderes populistas da democracia de 1945-1964}

O objetivo dessa seção, além de apresentar uma breve biografia política dos líderes populistas da democracia de 1945-1964, é apresentar a forte relação carismática com o povo que eles tiveram, ao longo dos anos, baseada na construção de políticas sociais e da imagem de defensores da população. Vargas, Barros, Quadros e Lacerda mais identificados com o populismo de direita (estatizante, nacionalista, tradicionalista, etc.), enquanto Brizola e Arraes mais aproximados com o populismo de esquerda (voltado para a emancipação da classe trabalhadora). Cabe ressaltar que políticos como Juscelino Kubitscheck e João Goulart tiveram forte vinculação partidária na sua trajetória sendo vistos mais como herdeiros do estilo Varguista de governo do que protagonistas de movimentos personalistas de poder. JKe Jango foram políticos com perfil mais conciliador com a classe política do que os políticos populistas, estes últimos propensos ao confronto político e a adesão das massas no seu projeto de governo.

Getúlio Vargas foi precursor desse estilo político de governar com uma interação direta com as"massas". No período do Estado Novo (1937-1945), Vargas reforçou o carisma conquistado durante a revolução de 1930 por meio da forte propaganda nacionalista, pelo combate ao comunismo e pela significativa ampliação de direitos sociais aos trabalhadores. Tudo isso em um cenário de forte controle estatal dos sindicatos, no qual Vargas desarticulou qualquer forma de insatisfação ou demandas operárias por greve, e de repressão sistematizada a qualquer forma de oposição ao seu poder. Tendo efetivado várias políticas públicas durante o tempo que ocupou a Presidência da República, Vargas reforçou no imaginário social que a melhora da situação dos trabalhadores dependia antes dele do que do sistema político (SOLA, 1969).

Sendo a figura que inspirou a criação dos principais partidos da época (PSD, UDN e PTB), Getúlio Vargas teve uma importância imensa na política brasileira. Durante o período 
que esteve fora da Presidência da República, de 1945 a 1950, concorreu em vários estados para diversos cargos, vencendo com larga margem de votos em quase todos os estados, escolhendo ser senador pelo Rio Grande do Sul. Seu carisma e prestígio pessoal ficaram intactos mesmo após os anos autoritários permitindo que voltasse a ocupar a Presidência da República, agora eleito pelas urnas, de 1950 até a sua morte fatídica em 1954. Aliás, a morte de Vargas representou o último momento de ligação dele com o povo que reagiu com pesar e fúria, destruindo algumas redações de jornais críticas ao finado Presidente, a partida do "pai dos pobres".

Em São Paulo, houve um terreno fértil para o surgimento de figuras populistas. Tanto que dois governadores paulistas com características populistas tiveram destaque nacional ao participarem das duas últimas eleições presidenciais: Adhemar de Barros e Jânio Quadros. O eleitorado paulista concedeu aos dois governadores paulistas a maioria dos seus votos nas respectivas eleições presidenciais de 1955 e 19604 . discurso populista desses líderes foi tão significativo que desequilibrou as votações dos principais partidos do país, no território paulista, já que a popularidade deles junto ao povo ultrapassava as urnas [...] "por certo, não se pode confundir povo com corpo eleitoral: a restrição do direito de voto aos alfabetizados afasta da atividade política (e em ampla medida elimina) a maioria da população adulta e a quase totalidade da população rural." (WEFFORT, 1978, p. 18).

Em grande medida, no entanto, os resultados das urnas ratificavam o capital político desses personagens.

Adhemar de Barros foi o fundador do Partido Social Progressista (PSP), em 1945, que foi uma máquina eleitoral durante as décadas de 50 e de 60 na cidade e no Estado de São Paulo. O partido assumiu duas vezes a prefeitura da capital paulista e três vezes o governo do Estado, sendo que na Câmara de Vereadores de São Paulo e na Assembleia Legislativa Estadual sempre teve a maior bancada de parlamentares. Durante esse período, a figura de Adhemar de Barros sempre referendou o sucesso eleitoral do PSP. Isso porque antes mesmo do retorno das eleições, na Era Vargas, Barros tinha sido interventor federal no estado de São Paulo. É dessa época que o contato dele com a

4 Segundo dados (Brasil, 2016), na eleição de 1955, Adhemar de Barros teve 45,8\% dos votos válidos do eleitorado de São Paulo. Em 1955, o contingente de eleitores era de 1.893.938. Na eleição de 1960, Jânio Quadros teve 55,1\% dos votos válidos do eleitorado paulista, em um contingente de 2.885 .441 eleitores. 
T\&P Regionalismo partidário e populismo no Brasil: análise da nacionalização dos partidos da democracia de 1945-1964

população do interior se intensificou devido a sua inserção frequente no rádio com uma linguagem mais próxima do homem simples do campo (DEBERT, 2008).

Essa será a grande diferença entre ele e seu principal concorrente no coração dos paulistanos: Jânio Quadros. Isso se tornaria um problema já que São Paulo era, e ainda é, o estado mais industrializado do país. Adhemar de Barros tinha seu eleitorado concentrado no setor rural, enquanto Jânio Quadros tinha seu eleitorado cativo no proletariado industrial. Tendo Quadros um discurso voltado às camadas trabalhadoras emergentes no cenário político, possibilitando uma projeção nacional atingindo até a Presidência da República, Barros terminou por ficar restrito ao território paulista, cujo discurso ideológico estava direcionado para a camada agrária (WEFFORT, 1965). Cabe salientar ainda que o tipo de liderança partidária feita por Barros controlava toda a máquina política do PSP impedindo, assim, que novas lideranças conseguissem alcançar os mesmos patamares de popularidade do chefe. Guita Debert (2008) aponta que esse pode ter sido um dos principais problemas do PSP para atingir uma força nacional já que o PSD tinha também uma base eleitoral rural para dispersar seus votos por todas as regiões.

Jânio Quadros é o exemplo marcante de político sintonizado com a população urbana. Com uma carreira política ascendente, ele foi eleito para ocupar o posto de vereador na primeira legislatura paulistana (1948-1951), sendo o propulsor da sua carreira política meteórica sua atuação incisiva como parlamentar na capital paulista. Depois ele foi eleito deputado estadual em 1950. Na eleição posterior, tornou-se prefeito de São Paulo, em 1953, deixando o posto em seguida para concorrer, com sucesso, ao governo do estado de São Paulo em 1954. Ainda foi eleito deputado federal em 1958, até chegar à Presidência da República em 1960. Em todas essas campanhas eleitorais teve uma espantosa votação a cada pleito (BAUAB, 2012; MANECHINI, 2012). Último chefe do Executivo nacional brasileiro a ser eleito de forma direta, antes da ditadura militar, Quadros tinha a plataforma de "varrer" a corrupção do país oriunda das irregularidades da construção de Brasília. No entanto, permaneceu pouco tempo como Presidente da República julgando existirem "forças ocultas" impedindo suas ações no governo federal.

Os próximos líderes populistas a serem retratados são aqueles que tinham a expectativa de assumir a Presidência da República, caso o golpe civil-militar de 1964 não tivesse ocorrido: Carlos Lacerda (UDN), Miguel Arraes (PST) e Leonel Brizola. Estes políticos estavam em ascensão na véspera da queda do regime democrático. Carlos Lacerda era 
um jornalista de formação que sempre foi um crítico feroz dos Presidentes, sendo um dos mais ferrenhos críticos de Vargas. A perseguição nos jornais aos mandatários do poder the rendeu uma tentativa de assassinato perpetrado por um dos seguranças de Vargas. No mesmo ano de seu atentado, em 1954, Lacerda apresentou sua candidatura a deputado federal pela UDN, sendo eleito com 150.000 votos, passando então a ser o grande líder da oposição varguista na Câmara (DEBERT, 2008).

De 1960 até 1964, Carlos Lacerda foi governador do Rio de Janeiro. Todavia, as sucessivas derrotas da UDN nas eleições presidenciais empurraram Lacerda para um apoio irrestrito ao golpe militar como solução ao comunismo que, em sua visão, estava próximo de desembarcar no país. Se podemos caracterizar Getúlio Vargas, Adhemar de Barros e Jânio Quadros como políticos populistas de direita ligados a valores conservadores, mas afastados de posições extremistas, Carlos Lacerda é o típico populista de direita que preza valores tradicionais da família e da religião católica. Assim, o comunismo seria uma ameaça nacional aceitando a necessidade de intervenção militar, provisória, para que a normalidade política voltasse ao país (BENEVIDES,1981).

Na definição de Ralf Melzer (2017), o populismo de direta emerge da confusão que o processo de modernização da sociedade causa na população. Na medida em que a sociedade se torna mais complexa, soluções que apelem para valores tradicionais são um refúgio para os cidadãos. Nesse espaço que atua o político populista jogando teorias conspiratórias para explicar a realidade aos cidadãos numa dicotomia de "nós", os bons cidadãos nacionalistas, versus "eles", os estranhos ou os corruptores dos valores nacionais (MELZER, 2017). No caso de Lacerda, o comunismo seria a grande "conspiração" internacional que atacaria a soberania do país e os valores da família brasileira, ou seja, seria o grande mal a ser combatido, se necessário, com intervenção militar no país. A classe média brasileira estava muito próxima dos valores defendidos por Lacerda, tanto que o golpe civil-militar foi bem aceito por essas camadas para deter o possível avanço do comunismo (SOARES, 2001).

Nos estados de Pernambuco e no Rio Grande do Sul, duas figuras expoentes e concorrentes do campo designado como populismo de esquerda foram, respectivamente, Miguel Arraes e Leonel Brizola. Para estes dois políticos, o povo precisava estar atento aos interesses da classe dominante que buscavam aumentar seus privilégios em detrimento dos interesses do povo. Arraes era um administrador eficiente que utilizou 
T\&P Regionalismo partidário e populismo no Brasil: análise da nacionalização dos partidos da democracia de 1945-1964

do seu prestígio junto as elites e a população para fazer transformações sociais em Recife e, depois, no estado de Pernambuco. Sua carreira política esteve sempre tomando direções alternativas na medida em que se posicionava contrário aos chefes políticos estaduais. Começou a carreira no PSD depois passou para a oposição udenista. Na UDN foi eleito prefeito de Recife, apoiado por uma ampla coligação de partidos contrários ao domínio do PSD, até ser eleito governador, em 1962, pelo PST. Durante quase toda sua carreira política teve a suspeita de ser considerado comunista pelos seus adversários, tanto progressistas quanto conservadores (DEBERT, 2008).

Leonel Brizola era outro político com forte viés progressista e com postulações de tornar-se Presidente da República, na programada eleição presidencial de 1965. Membro do PTB desde a sua fundação, foi o principal nome a se contrapor ao domínio pessedista no estado do Rio Grande do Sul, sendo eleito prefeito da capital gaúcha em 1956, e depois tornando-se governador estadual em 1958 (DEBERT, 2008). Foi no posto de governador do Rio Grande do Sul que sua visibilidade ganhou maior relevância dentro do estado e fora dele. Sua importância na política nacional pode ser dimensionada na Campanha da Legalidade, em 1961, na qual iniciou uma resistência armada contra a decisão de setores militares, apoiados por parte da opinião pública, de impedirem que o Vice-Presidente João Goulart ocupasse o posto vago de Presidente da República com a renúncia de Jânio Quadros. A ação articulada de Brizola e dos congressistas para que fosse mantido o rito constitucional de sucessão terminaram por manter João Goulart como chefe do Executivo de fato do país (FIGUEIREDO, 1993).

Depois desse acontecimento, a influência de Brizola sobre o Presidente Goulart, já que ambos eram do PTB, começou a causar atritos que indicavam uma forte intenção de Brizola ser o legítimo herdeiro político do trabalhismo varguista. O legado trabalhista de Vargas era a plataforma simbólica que Brizola carregava com enorme tenacidade para construir uma candidatura política viável no futuro, já que o Presidente Goulart cedia para um discurso apaziguador em meio a momentos de tensões na política nacional. Esse acirramento dentro do PTB foi mais uma das fagulhas para a direção autoritária que veio a ocorrer em 1964 (D’ARAÚJO, 1996). Em síntese, estes políticos foram figuras que discursaram sempre para o povo, em nome dele, como defensores de seus interesses contra um inimigo que estava à espreita de Ihes retirar direitos. 


\section{Metodologia}

A nacionalização partidária é uma forte agenda de pesquisa na Ciência Política brasileira. Sobre a democracia de 1945-1964 vários estudos recentes buscaram novas informações sobre aquela época por meio de indicadores e de dados empíricos mais apurados (NICOLAU, 2004, 2005; SANTOS, 2004). Nesse quesito, Santos (2004) salienta que os novos dados sobre aquela época, retificados por Nicolau (2004), não seriam tão essenciais para refutar análises precedentes de outros pesquisadores. Os dados das eleições para a Câmara dos Deputados eram incompletos em razão da dificuldade de coleta precisa para todos os estados via órgãos eleitorais. Em alguns casos, as votações dos candidatos ou dos partidos não eram separadas das coligações feitas para estas disputas eleitorais. O exaustivo processo de coleta de dados feito por Jairo Nicolau (2004) sobre as eleições para a Câmara dos Deputados possibilitou que fosse testada, nesta pesquisa, uma hipótese clássica da literatura que envolve muita discussão metodológica: a nacionalização partidária estaria ocorrendo nos principais partidos da época: PSD, UDN e PTB (NICOLAU, 2004, 2005; SANTOS, 2004).

Esta pesquisa está alinhada nesse debate mais aprofundado da dinâmica partidária de 1945-1964 através do referencial analítico da relação nacionalização versus regionalização. A nacionalização implica na capacidade de os partidos possuírem uma homogeneização de votos pelos estados. Os condutores desse processo são os partidos que precisam ter votações estáveis por todas as regiões de um país para envolver as diferentes comunidades em assuntos de interesse geral. O regionalismo seria uma fase arcaica e precária de estrutura da competição política, enquanto a nacionalização seria a fase moderna e profissionalizada (CARAMANI, 2004).

Os resultados apresentados pelos pesquisadores dessa temática indicam que sistemas partidários nacionalizados produziriam maiores incentivos para a efetivação de políticas públicas, para a estabilidade da competição eleitoral entre os grandes partidos e, não obstante, contribuiriam para o fortalecimento democrático. De outro lado, o regionalismo estaria conectado a práticas clientelistas entre representante e representados, fortalecendo líderes carismáticos em detrimento dos partidos, além de ser mais propicio à corrupção estatal por meio de práticas patrimonialistas (JONES; MAINWARING, 2003; CARAMANI, 2004; CHHIBBER; KOLLMAN, 2004). 
T\&P Regionalismo partidário e populismo no Brasil: análise da nacionalização dos partidos da democracia de 1945-1964

Na ótica dessa agenda de pesquisa, o sistema partidário só funcionaria de maneira plena quando a nacionalização dos partidos estivesse completa, pois os partidos só são estruturados quando possuem bases estáveis de votação por todo o território. Por isso a necessidade de uma verificação longitudinal da formação do eleitorado e da consolidação dos partidos. Contudo, a valoração do regionalismo político como algo negativo para a democracia impede de reconhecer uma característica de organização do sistema político de determinados países que favorece a descentralização de poder. Países com sistema político federativo podem realçar regionalismos partidários que podem ameaçar interesses de determinadas elites (econômicas, políticas ou militares).

Segundo Morgenstern (2005), a nacionalização partidária está ligada a duas dimensões de penetração territorial do voto: 1) dimensão estática - refere-se ao grau pelo qual o apoio partidário é consistente nos distritos; 2) dimensão dinâmica - refere-se ao grau pelo qual o movimento de apoio partidário é similar em vários distritos. Na dimensão estática, o que interessa é a capacidade do partido em promover estabilidade política na localidade. O partido precisa ser reconhecido como um porta-voz dos eleitores promovendo a estabilidade institucional da democracia. Na dimensão dinâmica, o que está em jogo é a capacidade competitiva do partido em ser viável eleitoralmente ao redor dos distritos onde busca um assento legislativo.

A correspondência das duas dimensões é de difícil mensuração no plano prático. Vários processos podem ser os geradores do sucesso eleitoral e não estar vinculados a nacionalização partidária, por exemplo: homogeneidade da população; características distritais; candidatos populistas; meios de comunicação (MORGENSTERN, 2005). Os processos que podem intervir na mensuração da nacionalização partidária só podem ser atenuados se a metodologia utilizada na pesquisa for eficiente em eliminar esses vieses.

Para analisar o fenômeno da nacionalização, é usado um índice recorrente nestes estudos, qual seja, o Party Nationalization Score (PNS) de Jones e Mainwaring (2003). Estes autores fizeram uma adaptação no uso do Coeficiente de Gini, índice muito usado na área econômica, para aplicação na Ciência Política. Na pesquisa de Jones e Mainwaring (2003), o coeficiente de Gini foi direcionado para a votação percentual desigual dos partidos nos diferentes estados, regiões e departamentos que compõe os territórios nacionais. Calcular essa dispersão/concentração de votos, de cada partido, implica 
mensurar os estados igualmente na análise. A fórmula do coeficiente de Gini aplicada aos dados eleitorais é:

$\mathrm{Gi}=\sum_{i=1}^{n}(X i Y i+1)-\sum_{i=1}^{n}(X i+1 Y i)$

onde:

$X i=$ é a proporção acumulada representada pelo percentual de votos válidos ganhos pelo Partido $X$ no estado $i$ dividido pela soma das percentagens vencida pelo Partido $X$ em todos os estados;

$Y_{i}=$ é a proporção cumulativa que qualquer estado representa no número total de estados ou outra subunidade política.

Este índice promove uma escala de valores, entre 0 e 1, onde os partidos que atinjam valores próximos de 1 (um) correspondem a nacionalização partidária, enquanto valores que se aproximem de 0 (zero) indicam uma regionalização partidária. Isso em razão do PNS ser o resultado do cálculo do coeficiente de Gini subtraído por 1, já que o interesse é medir a homogeneidade do voto partidário, sendo a expressão matemática desse cálculo:

PNS $=1-\mathrm{Gi}$

Este índice servirá para mensurar a nacionalização, ou regionalização, dos principais partidos do período de 1945-1964. Nessa análise da nacionalização, será esperado que os partidos que contaram nas suas fileiras com políticos com perfil populista - Getúlio Vargas (PTB), Jânio Quadros (PDC/PTN), Adhemar de Barros (PSP), Carlos Lacerda (UDN), Miguel Arraes (PST) e Leonel Brizola (PTB) -, apresentem pontuações mais próximas de partidos regionalizados do que nacionalizados já que o discurso antagonista de "nós" versus"outros" pode ter contribuído para uma diminuição de potencial de votos destes partidos.

\section{Análise dos dados empíricos}

No começo da democracia de 1945-1964, as eleições majoritárias estaduais eram dominadas pelo PSD e pela UDN. O processo eleitoral para os governos estaduais continha quase as mesmas diretivas daquelas requeridas para a eleição presidencial. 
T\&P Regionalismo partidário e populismo no Brasil: análise da nacionalização dos partidos da democracia de 1945-1964

A excepcionalidade estava na duração do mandato do chefe do executivo estadual que dependia das decisões de cada estado (NICOLAU, 2012). Essa duração diferente do mandato permitia que acontecessem eleições para governadores estaduais em ciclos eleitorais distintos. Na Tabela 1, temos as primeiras informações sobre a força dos partidos, nos estados, nas eleições majoritárias para Governador.

Tabela 1. Número de Governadores eleitos por partido (1947-1962).

\begin{tabular}{lcccccc}
\hline & \multicolumn{7}{c}{ UF } & PSD & UDN & PTB & PSP & PST & Outro \\
\cline { 2 - 7 } & 2 & 1 & - & 1 & - & - \\
\hline Alagoas & 1 & 1 & 2 & - & - & - \\
\hline Amazonas & 1 & 2 & - & - & - & 1 \\
\hline Bahia & 1 & 2 & - & - & - & 1 \\
\hline Ceará & 2 & - & 1 & - & - & 1 \\
\hline Espírito Santo & 3 & 1 & - & - & - & - \\
\hline Goiás & 2 & - & - & - & 1 & 1 \\
\hline Maranhão & 2 & 2 & - & - & - & - \\
\hline Mato Grosso & 2 & 2 & - & - & - & - \\
\hline Minas Gerais & 3 & 1 & - & - & - & - \\
\hline Pará & 1 & 1 & - & - & - & 2 \\
\hline Paraíba & 1 & 1 & - & - & - & 2 \\
\hline Paraná & 3 & - & - & - & 1 & - \\
\hline Pernambuco & 3 & 1 & - & - & - & - \\
\hline Piauí & 1 & 1 & 1 & - & - & 1 \\
\hline Rio de Janeiro & 2 & - & - & 2 & - & - \\
\hline Rio Grande do Norte & 3 & - & 1 & - & - & - \\
\hline Rio Grande do Sul & 2 & 2 & - & - & - & - \\
\hline Santa Catarina & - & - & - & 3 & - & 1 \\
\hline São Paulo & 3 & 1 & - & - & - & - \\
\hline Sergipe & 38 & 19 & 5 & 6 & 2 & 10 \\
\hline TOTAL & & & & & & \\
\hline
\end{tabular}

Fonte: Brasil (2016).

Os dados mostram que o PSD e a UDN foram eficientes em assumir o controle, por mais vezes, dos governos estaduais alicerçado, possivelmente, no antagonismo chave entre apoiadores e críticos do legado de Getúlio Vargas. Os dois partidos obtiveram governos em quase todas as regiões do país. O PTB, no entanto, teve um sucesso eleitoral nos estados aquém do esperado de um partido visto na literatura como predestinado a ser dominante no sistema político. Importante ressaltar que no caso da UDN, a opção de se contrapor ao legado getulista ou de compor alianças com outros partidos permitiu que o partido tivesse o segundo posto em número de governos estaduais conquistados. 
Nos casos de PTB, PSP e PST a chegada dos governos estaduais foi alcançada, em grande parte, por um líder populista. Isso aconteceu no Rio Grande do Sul e em Pernambuco, com Leonel Brizola e com Miguel Arraes, para se contrapor ao predomínio do PSD, enquanto em São Paulo temos um reduto do PSP que obteve 50\% dos cargos de governador neste estado por meio da popularidade de Adhemar de Barros. Esses dados da eleição para governador estadual são indicativos da dificuldade que os partidos brasileiros tinham de ser competitivos em todo o território.

As informações sobre as disputas parlamentares, nacional e estadual, trarão mais precisão sobre esse e outros pontos. Como terá sido a nacionalização destes partidos frente aquela sigla que não teve uma liderança fortemente vinculada com este perfil populista, especificamente, o PSD? Os partidos destes líderes populistas possuem a mesma força em todos os estados brasileiros? Por acaso coincidiria os períodos de maior regionalização partidária quando as legendas tinham políticos populistas nos principais postos do Executivo? A nacionalização partidária estaria ocorrendo nos principais partidos, notadamente, PSD, UDN e PTB como menciona parte da literatura?

Na Tabela 2, a seguir, temos os valores do Party Nationalization Score (PNS) nas disputas para o cargo de deputado federal. Os estados analisados que tinham informações completas dos votos válidos dos partidos na eleição de 1945 são: Acre, Alagoas, Amazonas, Bahia, Ceará, Distrito Federal, Espírito Santo, Goiás, Maranhão, Mato Grosso, Minas Gerais, Pará, Paraíba, Paraná, Pernambuco, Piauí, Rio de Janeiro, Rio Grande do Norte, Rio Grande do Sul, Santa Catarina, São Paulo e Sergipe. Nas eleições seguintes (1950, 1954, 1958 e 1962) foram acrescidos na análise os estados do Amapá, Rondônia e Roraima.

Dos partidos tradicionais, apenas o PSD obteve um alto índice de nacionalização durante a democracia de 1945-1964, se colocado o ponto de corte para uma alta nacionalização valores acima de PNS=0,70. Na média, o PSD sempre foi um partido

Tabela 2. PNS nas eleições para a Câmara dos Deputados.

\begin{tabular}{cccccccc}
\hline \multirow{2}{*}{ Ano } & \multicolumn{7}{c}{ Partidos Políticos } \\
\cline { 2 - 9 } & PSD & UDN & PTB & PSP & PST & PDC & PTN \\
\hline 1945 & 0,87 & 0,83 & 0,53 & - & - & 0,49 & - \\
\hline 1950 & 0,78 & 0,69 & 0,60 & 0,47 & 0,47 & 0,64 & 0,72 \\
\hline 1954 & 0,79 & 0,63 & 0,68 & 0,58 & 0,62 & 0,50 & 0,85 \\
\hline 1958 & 0,79 & 0,65 & 0,64 & 0,53 & 0,78 & 0,48 & 0,79 \\
\hline 1962 & 0,80 & 0,64 & 0,72 & 0,47 & 0,48 & 0,47 & 0,47 \\
\hline Média & 0,81 & 0,69 & 0,63 & 0,51 & 0,59 & 0,51 & 0,71 \\
\hline Fonte: Brasil (2016). & & & & & & &
\end{tabular}


T\&P Regionalismo partidário e populismo no Brasil: análise da nacionalização dos partidos da democracia de 1945-1964

nacionalizado em razão de ele ter sido o primeiro partido a ter uma estrutura organizativa completa nos estados. A redução de sua nacionalização, em 1950, pode ter sido ocasionada pelo fracasso do plano econômico do governo de Eurico Dutra (1945-1950). Jairo Nicolau (2004) aponta também que os resultados da primeira eleição democrática são sempre discrepantes do que ocorrerá ao longo dos ciclos eleitorais, nos quais novos competidores ganharão apoio do eleitorado em razão ou do papel como oposicionistas, ou dos insucessos do partido governista. A UDN teve uma estabilidade de votação nos estados durante os ciclos eleitorais ficando, na média, muito perto de ser um partido nacionalizado. Já o PSP, partido de porte médio, teve uma fraca nacionalização durante o período, sendo bem oscilante na sua inserção nos estados.

Os dados empíricos permitiram testar uma hipótese bastante difundida entre os pesquisadores desse momento político brasileiro que credita o crescimento eleitoral do PTB ancorado na extinção do Partido Comunista Brasileiro (SOARES, 2001; SANTOS, 2004; NICOLAU, 2005). Não consta na Tabela 2 as informações sobre o PCB, pois a sigla participou apenas da eleição de 1945, mas nessa eleição o partido comunista atingiu um valor de nacionalização partidária de 0,67 tonando-se, desse modo, o terceiro partido em homogeneidade de votos pelos estados. O PTB, que na eleição de 1945 era um partido mais regionalizado, partindo de um valor de PNS=0,53 alcançou na última eleição democrática, em 1962, valor de PNS=0,72. Percebe-se que essa hipótese clássica da literatura de transferência direta do voto comunista para o voto trabalhista pode ter ocorrido.

O PTB cresceu muito a cada ciclo eleitoral, atingindo seu ápice de nacionalização após a chegada de João Goulart à Presidência da República. O PTB tinha raízes com a base sindical dando-Ihe suporte para servir aos interesses dessa camada ascendente na participação política. Sendo um partido com ideologia trabalhista definida e se beneficiando da falta de um concorrente na disputa pelo eleitorado operário, logo que o PCB foi posto na ilegalidade em 1947, o PTB tornou-se o baluarte dos interesses da classe operária. O PTB foi quem mais cresceu eleitoralmente na Câmara dos Deputados, do começo do sistema partidário de 1945-1964 até o seu final (SOARES, 2001). É de se supor que o voto comunista, além de ser transferido de maneira dispersa para os partidos emergentes, contribui muito para a ascensão eleitoral do PTB. 
Uma ressalva deve ser feita quanto aos eventuais altos índices de nacionalização dos partidos nanicos (PST, PDC e PTN). Estes partidos atingiram percentuais de votos válidos quase sempre nulos ou inferiores à 1\% em todos os estados analisados nesta pesquisa, ou seja, há um fraco apelo eleitoral destes partidos nas eleições parlamentares se formos mensurar as duas dimensões, estática e dinâmica, de um partido. Foram partidos sem concentração de votos em um estado específico e sem competitividade nas diferentes regiões do país. A recomendação dos pesquisadores sobre nacionalização é evitar colocar estes partidos nanicos na análise por causa dessa influência negativa nos resultados aparentando uma nacionalização que esconde a caótica organização partidária que não consegue lançar candidatos competitivos em vários estados (JONES; MAINWARING, 2003; MORGENSTERN, 2005). Neste caso, de análise do populismo, prefiro mostrar a fraca nacionalização destes partidos nanicos para ressaltar como a presença de lideranças populistas destes partidos, Miguel Arraes e Jânio Quadros, tiveram maior êxito que suas legendas. E que o sucesso eleitoral proveniente destes políticos populistas esconde a pouca importância destes partidos no sistema partidário de 1945-1964. Isso é exemplificado na Tabela 3.

Tabela 3. Total de votos válidos obtidos, por partido, para a Câmara dos Deputados (\%).

\begin{tabular}{cccccccc}
\hline \multirow{2}{*}{ Ano } & \multicolumn{7}{c}{ Partidos Políticos } \\
\cline { 2 - 8 } & PSD & UDN & PTB & PSP & PST & PDC & PTN \\
\hline 1945 & 42,4 & 26,8 & 10,2 & - & - & 1,7 & - \\
\hline 1950 & 32,8 & 24,3 & 18,5 & 9,7 & 2,2 & 1,1 & 2,8 \\
\hline 1954 & 32,6 & 21,9 & 18,7 & 11,2 & 0,4 & 1,6 & 2,2 \\
\hline 1958 & 33,6 & 21,1 & 20,5 & 6,3 & 1,1 & 3 & 2,5 \\
\hline 1962 & 30,1 & 22,6 & 24,8 & 4,9 & 1,7 & 5,5 & 2,8 \\
\hline
\end{tabular}

Fonte: Brasil (2016).

Os campos sem preenchimento indicam que não há informação disponível sobre este partido pela ausência dele no pleito. Nesta Tabela 3 fica evidente a disparidade de votação dos partidos tradicionais - PSD, UDN e PTB -, se comparado com a homogeneidade de votos pelos estados. O PTB teve um progressivo crescimento eleitoral, como apontado pela literatura, em razão da incorporação da camada trabalhadora, sem demasiadas restrições, no processo eleitoral (LIMONGI, 2015). PSD e UDN diminuíram suas votações de 1945, mas tiveram estabilidade de votação durante os sucessivos pleitos, ficando no patamar, respectivamente, de 30\% e de 20\% dos votos válidos. 
T\&P Regionalismo partidário e populismo no Brasil: análise da nacionalização dos partidos da democracia de 1945-1964

Agora parto para a análise da nacionalização no nível subnacional. Na Tabela 4, verifico a nacionalização nos estados analisados que tinham informações completas dos votos válidos dos partidos para os cargos de deputados estaduais: Alagoas, Amazonas,

Tabela 4. PNS nas eleições para as Assembleias Estaduais.

\begin{tabular}{cccccccc}
\hline \multirow{2}{*}{ Ano } & \multicolumn{7}{c}{ Partidos Políticos } \\
\cline { 2 - 8 } & PSD & UDN & PTB & PSP & PST & PDC & PTN \\
\hline 1947 & 0,86 & 0,79 & 0,67 & 0,53 & - & 0,63 & 0,49 \\
\hline 1950 & 0,71 & 0,65 & 0,66 & 0,63 & 0,56 & 0,53 & 0,58 \\
\hline 1954 & 0,88 & 0,71 & 0,77 & 0,75 & 0,46 & 0,53 & 0,56 \\
\hline 1958 & 0,81 & 0,77 & 0,71 & 0,66 & 0,50 & 0,51 & 0,49 \\
\hline 1962 & 0,75 & 0,71 & 0,75 & 0,58 & 0,49 & 0,62 & 0,47 \\
\hline Média & 0,80 & 0,72 & 0,71 & 0,63 & 0,50 & 0,56 & 0,52 \\
\hline
\end{tabular}

Fonte: Brasil (2016).

Bahia, Ceará, Espírito Santo, Goiás, Maranhão, Mato Grosso, Minas Gerais, Pará, Paraíba, Paraná, Pernambuco, Piauí, Rio de Janeiro, Rio Grande do Norte, Rio Grande do Sul, Santa Catarina, São Paulo e Sergipe. Nota-se na Tabela 4 que, diferente do que ocorreu no nível nacional, os três partidos tradicionais da democracia de 1945-1964 atingem altos índices de nacionalização partidária nas disputas para as Assembleias Estaduais corroborando o que a literatura que pesquisa esta época salienta de um jogo de forças equilibrado em poucos partidos (BENEVIDES, 1981; HIPPOLITO, 1985; CAMPELO DE SOUZA, 1985; D'ÁRAUJO, 1996; LAVAREDA, 1999; SOARES, 2001).

OPSD, novamente, teve média alta de PNS=0,80, enquanto UDN e PTB, respectivamente, tiveram $P N S=0,72$ e PNS=0,71. A hipótese dessa pesquisa que creditava uma interferência negativa do populismo quanto mais próximo do nível regional não se confirmou, pelo contrário a nacionalização foi maior no nível subnacional do que no nível nacional para os principais partidos. É presumível supor que esse nível alto de nacionalização seja decorrente da rápida organização partidária dessas siglas nos primeiros anos democráticos depois da queda do Estado Novo.

Denota-se da Tabela 4 que quanto mais importante o cargo em disputa - Presidente da República, Governador, Deputado Federal -, mais difícil para os pequenos partidos conseguirem atingir um eleitorado maior. A força destes partidos políticos emergentes esteve alicerçada no nível local, sendo que a presença de lideranças populistas não impediu uma penetração maior destes partidos emergentes nas Assembleias Estaduais. 
Nos resultados eleitorais subnacionais aqui analisados percebe-se que os partidos tradicionais tiveram o desempenho esperado de forte homogeneização dos votos por todos os estados. Na Tabela 5, apresento o total de votos válidos dessa disputa de deputado estadual.

Tabela 5. Total de votos válidos obtidos, por partido, para as Assembleias Estaduais (\%).

\begin{tabular}{cccccccc}
\hline Ano da & \multicolumn{7}{c}{ Partidos Políticos } \\
\cline { 2 - 8 } Eleição & PSD & UDN & PTB & PSP & PST & PDC & PTN \\
\hline 1947 & 32 & 23,8 & 14,1 & 4,5 & - & 1,4 & 1,5 \\
\hline 1950 & 23,5 & 20,7 & 15,9 & 8,3 & 2,6 & 2,3 & 3,5 \\
\hline 1954 & 29,2 & 17,5 & 16,1 & 12,7 & 2,6 & 3,5 & 2,3 \\
\hline 1958 & 23,4 & 28,4 & 13,4 & 9,1 & 2,3 & 4,7 & 3,7 \\
\hline 1962 & 21,6 & 16,1 & 17,2 & 9,9 & 4,2 & 9 & 5,3 \\
\hline
\end{tabular}

Fonte: Brasil (2016).

Para efeito de comparação, novamente, nesta Tabela 5 fica aparece a disparidade de votação dos partidos tradicionais frente os partidos de pequeno porte. No entanto, a votação dos partidos emergentes aumentou se comparado com a esfera nacional. O PTB teve estável votação no período, enquanto PSD e UDN tiveram uma grande redução de votos de 1947 até 1962. Esses dados reforçam o argumento de que os partidos conservadores estavam perdendo espaço na democracia de 1945-1964 e de que os partidos pequenos eram mais competitivos no nível subnacional do que nas disputas para cargos nacionais (SOARES, 2001). Desse modo, a regionalização dos partidos da democracia de 1945-1964 não foi um dos fatores a contribuir para o fim deste sistema partidário, pois os partidos tinham estáveis valores de nacionalização pelos estados.

\section{Conclusão}

No senso comum, populismo é um conceito utilizado com conotações estigmatizadas pela possibilidade de manipulação das massas pesar sobre os ombros dos políticos que carregam essa alcunha de "populistas". Os políticos definidos como "populistas" pela opinião pública seriam fruto de uma população desinformada que não leva em conta os interesses estritamente particularistas desses políticos. Ou seja, ser populista corresponde, para grande parte da população, em um político que toma decisões 
T\&P Regionalismo partidário e populismo no Brasil: análise da nacionalização dos partidos da democracia de 1945-1964

demagógicas em prol da sua continuidade política, e não pensando nos interesses do eleitorado. Atualmente, essa crítica recai sobre a grande maioria dos políticos brasileiros, e também latino-americanos, sendo descrita como uma onda de neopopulismo latino-americano, vide a ascensão, nos anos 2000, de figuras carismáticas controversas como Hugo Chávez, Néstor Kirchhner, Evo Morales, etc. que trabalharam na alteração de suas respectivas constituições para permanecerem no poder indefinidamente.

Essa pesquisa buscou fugir dessas concepções negativas sobre este conceito tentando mensurar um de seus possíveis efeitos, qual seja, o populismo poderia ter sido um dos fatores de fraca nacionalização do sistema partidário. A democracia brasileira de 1945-1964 ficou reconhecida como sendo um período de proliferação deste estilo de fazer política. Por isso a atenção nesta pesquisa para tentar compreender se o populismo afetou a nacionalização partidária das principais siglas da época. Os resultados da nacionalização partidária, no entanto, sugerem, apesar do partido mais nacionalizado, o PSD, estar imune à presença de políticos populistas, refutar a hipótese de que a nacionalização dos partidos foi reduzida quando esteve presente, dentro das legendas, políticos populistas.

Isso pode ser exemplificado de duas maneiras. Em primeiro lugar, o crescimento de nacionalização partidária do PTB ao longo da década de 1960, no nível nacional, já que essa sigla contou com líderes populistas que arregimentavam a população: Getúlio Vargas e Leonel Brizola. A falta de concorrentes no campo trabalhista propiciou que o PTB fosse o principal beneficiário da extensão do sufrágio para a classe operária, pois o PCB, partido que na eleição de 1945 apresentou uma nacionalização média, foi colocado na clandestinidade. A segunda razão para negar a hipótese de influência negativa do populismo no sistema partidário foram os resultados de nacionalização no nível subnacional, nos quais a possível interferência negativa do populismo, na capacidade de os partidos estarem mais homogêneos de votação nos estados, deveria ser mais evidente mostrou-se sem efeito. Nas Assembleias Estaduais, além dos partidos tradicionais (PSD, UND e PTB), o PSP também tinha bastante alcance nos estados chegando, na média, a ficar próximo do ponto de corte de alta nacionalização, ou seja, em torno de 0,70. E os demais partidos (PST, PDC e PTN) tiveram estabilidade de votação nos estados, ou seja, nem subindo nem decaindo.

O intuito dessa pesquisa foi responder uma série de questões sobre o passado da política brasileira que estavam ainda encobertas por dúvidas. O diagnóstico de que o 
golpe civil-militar de 1964 teve o intuito de barrar a ascensão de líderes populistas e dos partidos trabalhistas mostra-se pouco produtivo na medida em que os partidos tiveram padrões de nacionalização estáveis, com a exceção do PTB que teve um forte crescimento, durante esta curta experiencia democrática. O populismo mostrou-se um fenômeno desconectado ao regionalismo partidário tanto nas eleições para a Câmara dos Deputados, quanto para as eleições para as Assembleias Estaduais, sendo improdutivo para explicar a crise desse sistema partidário que resultou no gol pe civil-militar de 1964. Partidos que tiveram lideranças populistas vencendo disputas aos cargos do Executivo, cujo tipo de eleição depende muito do carisma do candidato para ocupação do cargo majoritário, não acarretou em prejuízo nas disputas parlamentares nos estados. Portanto, pode-se conjecturar que a fraca nacionalização dos partidos, no nível nacional, esteve pautada muito em falhas de organização partidária do que por motivos de personalização das principais lideranças partidárias.

O aspecto da nacionalização/regionalismo do sistema partidário de 1945-1964 mostrou-se ser um bom teste para questionar o argumento vigente de que o populismo afeta negativamente o sistema partidário já que tanto no Brasil, quanto em outros países da América Latina, essa parece ser uma discussão permanente em razão da crise dos partidos. Talvez a instabilidade destas democracias esteja alicerçada na incapacidade dos principais partidos conseguirem, de maneira organizada, ter uma presença por todo território e pelos sucessivos escândalos de corrupção administrativa. Os criticados políticos com viés "populista" até podem ser um dos principais problemas para a consolidação desses sistemas políticos e, por conseguinte, da democracia, porém esta pesquisa mostrou que os efeitos negativos do populismo podem ser neutralizados, ou amenizados, no ambiente partidário.

\section{Agradecimentos}

Gostaria de agradecer imensamente aos pareceristas da revista pela leitura atenta e rigorosa, pelas indicações de bibliografia e de revisão dos dados empíricos, que melhoraram em muito a versão final deste artigo. 
T\&P Regionalismo partidário e populismo no Brasil: análise da nacionalização dos partidos da democracia de 1945-1964

\section{Referências}

BAUAB, J. A primeira eleição ao parlamento paulistano pós-ditadura Vargas e o drama dos vereadores comunistas. In: SÃO PAULO. Câmara Municipal de. São Paulo na Tribuna: a primeira legislatura (1948-1951). São Paulo: Imprensa Oficial do Estado de São Paulo, 2012.

BENEVIDES, M. V. 1981. A UDN e o udenismo: ambiguidades do liberalismo brasileiro (1945-1965). Rio de Janeiro: Paz e Terra.

BRASIL. Tribunal Superior Eleitoral -TSE. Brasília, 2016. Disponível em: <http://www.tse.jus.br/>. Acesso em: 13 set. 2016.

CAMPELO DE SOUZA, M. O processo político partidário na Primeira República. In: MOTA, C. (Ed.). Brasil em perspectiva. São Paulo: Difel, 1969.

CAMPELO DE SOUZA, M. A Democracia Populista de 1945-1964: Bases e Limites. In: ROUQUIÉ, A.; LAMOUNIER, B.; SCHVARZER, J. (Ed.). Como renascem as democracias. São Paulo: Brasiliense, 1985.

CARAMANI, D. The nationalization of politics: the formation of national electorates and party systems in Western Europe. Cambridge: Cambridge University Press, 2004.

CERVI, E. As sete vidas do populismo. Revista de Sociologia e Politica, v. 17, p. 151-156, 2001.

CHHIBBER, P.; KOLLMAN, K. The formation of national party systems:federalism and party competition in Canada, Great Britain, India, and the United States. Princeton: Princeton University Press, 2004.

D’ARAÚJO, M. C. Sindicatos, carisma e poder: o PTB de 1945-65. Rio de Janeiro: FGV, 1996.

DEBERT, G. Ideologia e populismo: Adhemar de Barros, Miguel Arraes, Carlos Lacerda, Leonel Brizola. Rio de Janeiro: Centro Edelstein de Pesquisas Sociais, 2008.

FERREIRA, J. O nome e a coisa: o populismo na política brasileira. In: FERREIRA, J. (Ed.). O populismo e sua história: debate e crítica. Rio de Janeiro: Civilização Brasileira, 2001.

FIGUEIREDO, A. Democracia ou reformas? Alternativas democráticas à crise política: 1961-1964. São Paulo: Paz e Terra, 1993.

GOMES, A. O Populismo e as Ciências Sociais no Brasil: notas sobre a trajetória de um conceito. In: FERREIRA, J. (Ed.). O populismo e sua história: debate e crítica. Rio de Janeiro: Civilização Brasileira, 2001.

HIPPOLITO, L. De raposas e reformistas: o PSD e a experiência democrática brasileira (1945-64). Rio de Janeiro: Paz e Terra, 1985.

JONES, M.; MAINWARING, S. The Nationalization of parties and party systems: an empirical measure and an application to Americas. Kellogg Institute Working Paper, v. 1, n. 304, p. 1-30, 2003.

LACLAU, E. Populism: what's in a name? In: PANIZZA, F. Populism and the mirror of democracy. London: Verso, 2005. 
LAVAREDA, A. A democracia nas urnas. Rio de Janeiro: Revan, 1999.

LEAL, V. Coronelismo, enxada e voto. São Paulo: Alfa-Omega, 1975.

LIMONGI, F. Fazendo Eleitores e Eleições: mobilização política e democracia no Brasil Pós-Estado Novo. Dados: Revista de Ciências Sociais, v. 58, n. 2, p. 371-400, 2015.

MANECHINI, L. De vereador a Presidente da República. In: SÃO PAULO. Câmara Municipal de. São Paulo na Tribuna: a primeira legislatura (1948-1951). São Paulo: Imprensa Oficial do Estado de São Paulo, 2012.

MELZER, R. Populismo de derecha en Alemania: un desafío para la democracia. Nueva Sociedad, v. 267, p. 88-100, 2017.

MORGENSTERN, S. Questions of party nationalization. Washington: American Political Science Association, 2005. p. 1-23.

NICOLAU, J. Partidos na República de 1946: velhas teses, novos dados. Dados: Revista de Ciências Sociais, v. 47, n. 1, p. 85-129, 2004.

NICOLAU, J. Partidos na República de 1946: uma réplica metodológica. Dados: Revista de Ciências Sociais, v. 48, n. 3, p. 589-609, 2005.

NICOLAU, J. Eleições no Brasil: do Império aos dias atuais. Rio de Janeiro: Zahar, 2012.

PANIZZA, F. Introduction: populism and the mirror of Democracy. In: PANIZZA, F. Populism and the mirror of democracy. London: Verso, 2005.

RICCI, P.; ZULINI, J. Partidos, Competição Política e Fraude Eleitoral: a tônica das eleições na Primeira República. Dados: Revista de Ciências Sociais, v. 57, n. 2, p. 443-479, 2014.

SANTOS, W. G. Velhas teses, novos dados: uma análise metodológica. Dados: Revista de Ciências Sociais, v. 47, n. 4, p. 729-762, 2004.

SCHATTSCHNEIDER, E. The semisovereign people: a realist's view of democracy in America. New York: Holt, Rinehart, and Winston, 1960.

SOARES, G. A democracia interrompida. Rio de Janeiro: FGV, 2001.

SOLA, L. O Golpe de 37 e o Estado Novo. In: MOTA, C.G. (Ed.). Brasil em perspectiva. São Paulo: Difel, 1969.

WEFFORT, F. As raízes sociais do populismo em São Paulo. Revista Civilização Brasileira, v. 2, p. 39-60, 1965.

WEFFORT, F. O populismo na política brasileira. São Paulo: Paz e Terra, 1978.

Recebido: 06 fev., 2017

Aceito: 18 abr., 2017 